\title{
Las reformas de Augusto en los munera gladiatoria
}

\author{
Mauricio PASTOR MuÑOZ \\ Universidad de Granada \\ mpastor@ugr.es
}

\section{RESUMEN}

Los munera gladiatoria fueron los más populares de los ludi que se ofrecían en Roma y en las provincias del Imperio. Augusto fue esencial en la historia de la gladiatura, al igual que lo fue en tantas otras áreas de la vida e historia de Roma. Durante el Imperio, los políticos ya no tenían poder para decidir por sí mismos sobre los munera, sino que era el emperador el único que tenía autoridad sobre los juegos. Augusto utilizó el munus como uno de los instrumentos para construir su Imperio y, en consecuencia, decidió dar una organización más precisa al espectáculo gladiatorio, reglamentándolo de un modo minucioso. En este breve trabajo, mediante el análisis de los textos clásicos, ofrecemos los aspectos fundamentales de las reformas de Augusto que afectaron, especialmente, a las luchas de gladiadores, que tanto divertían a los ciudadanos de Roma y las provincias.

Palabras clave: Augusto. Imperio. Juegos de gladiadores. Munera. Roma.

\section{Augustus' Reforms in the Munera Gladiatoria}

\begin{abstract}
The munera gladiatoria were the most popular ludi among those offered in Rome and the other provinces of the Empire. Augustus played a crucial role in the history of the profession of gladiator. In fact, during the Empire, politicians were no longer able to decide about the munera. Rather, it was only the emperor who had any authority over the games. Augustus used the munus as one of the instruments to build his Empire. In that respect, he decided to provide gladiator performances with an organized structure, devising a meticulous system of regulations. This paper analyzes Augustus' reformations and the impact they had on gladiator fights, which so much entertained Roman audiences.
\end{abstract}

Key Words: Augustus. Empire. Gladiator's games. Munera. Rome. 
De todos los espectáculos que se ofrecían en Roma y en las provincias del Imperio, los munera gladiatoria eran los más populares. También, hoy día, las luchas de gladiadores levantan un gran interés entre la gente, fascinada por muchos de los aspectos que rodeaban aquellas luchas y la vida de aquellos hombres. Libros, artículos, películas, series de televisión y muchos otros productos culturales aparecen cada año en el mercado para continuar alimentando esa fascinación por el tema. ${ }^{1}$ Pero, con frecuencia, esos productos extienden entre la opinión pública ideas erróneas sobre el espectáculo gladiatorio. Razón por la cual quiero aprovechar este congreso sobre el Bimilenario de Augusto para aclarar algunos conceptos sobre el mundo de los gladiadores y, especialmente, sobre las reformas llevadas a cabo por Augusto que afectaron, evidentemente, al desarrollo del munus. ${ }^{2}$

Como en otras áreas de la vida e historia de Roma (Fig. 1). Durante el Imperio, los políticos ya no tenían poder para decidir por sí mismos sobre los munera, sino que era el emperador el único que tenía autoridad sobre los juegos. Así, el Princeps decidió dar una organización más precisa al espectáculo gladiatorio, reglamentándolo de un modo minucioso y dándole una nueva organización.

Para Kyle, "Augusto comprendió la popularidad del deporte [gladiatorio] y el valor que tenía para las relaciones públicas, por lo que puso en marcha una muy concienzuda y exitosa política de juegos y espectáculos". ${ }^{3}$ La reforma augusta fue parte esencial de dicha política, pues solo un espectáculo bien definido podía poseer la calidad que se necesitaba para lograr los fines que se proponía: convertirlo en el deporte nacional del Imperio, romanizar los nuevos territorios y entretener al pueblo. Una vez tuvo el nuevo deporte que deseaba se lanzó a usarlo como ningún político había hecho antes. En palabras de Suetonio: "[Augusto] sobrepasó a todos sus predecesores en la frecuencia, variedad y magnificencia de sus espectáculos públicos". ${ }^{4}$ Augusto utilizó el espectáculo gladiatorio como uno de los instrumentos para construir su Imperio.

Según Junkelmann: "obviamente la reorganización de los combates gladiatorios a comienzos del Imperio no conllevó una ruptura completa con el pasado. Más bien fue un proceso deliberado de selección y mejora de lo que ya existía, aclarando y estandarizando los elementos que antes eran ambiguos. La escasez de las fuentes materiales hace más difícil conocer cuáles eran las tradiciones sobre las que se basó esta reforma que observar sus resultados". ${ }^{5}$ Veamos, pues, los antecedentes previos a la reforma de Augusto.

1 Un tema, sin duda, apasionante y de enorme actualidad, puesto que son muchas las obras que tienen al "gladiador romano" como auténtico protagonista (Ben-Hur, Espartaco, Pollice verso de Jean-León Gérome, donde se representa el momento supremo de un combate de gladiadores, Gladiator de Ridley Scott, o la nueva serie televisiva Spartacus). Gracias a ellas, los espectadores de la sociedad actual podemos conocer algunos de los aspectos más increíbles del mundo romano.

2 Sobre otros aspectos del munus, cf. Pastor 2002, 485-499; Pastor 2007, 187-202; Pastor 2008, $395-$ 405; PASTOR 2011, 213-230; PASTOR - MAÑas 2010, 291-321; PASTOR - MAÑas 2012, 127-151; PASTOR MuÑoz - Pastor Andrés 2008, 163-206; PAStor MuÑoz - Pastor Andrés 2009, 171-199; PAStor MuÑoz - Pastor ANDRÉS 2013a, 259-276; PASTOR MuÑoz - PASTOR ANDRÉS 2013b, 127-152.

3 KYLE 2007, 289.

4 Suet., Augustus 43.1.

5 JunkelmanN 2000, 35. 


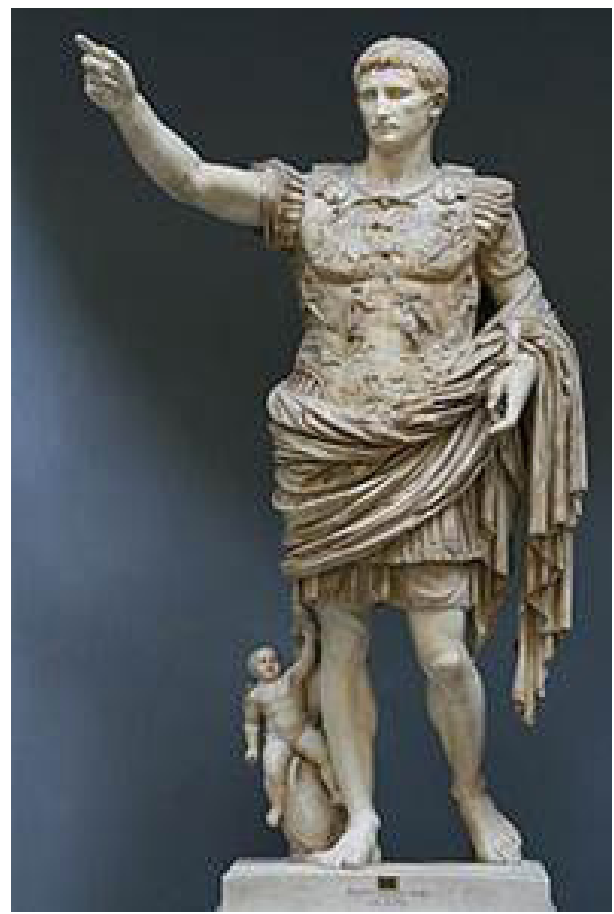

Fig. 1. Estatua del Emperador Augusto.

En la Antigua Roma el espectáculo consistente en ofrecer luchas de gladiadores se llamaba munus (“deber", “obligación”) porque originalmente esta práctica era una obligación fúnebre que se tenía con el difunto recién fallecido; los familiares más allegados tenían el "deber" de ofrecer en memoria del muerto un combate de gladiadores (munus gladiatorum), con la idea de que la sangre del gladiador vencido favoreciese al espíritu del fallecido en la otra vida. Esta vinculación fúnebre inicial se perdió con el tiempo, pero el término munus se mantuvo durante toda la época romana para designar al espectáculo gladiatorio.

El munus fue perdiendo la relación con lo fúnebre, al mismo tiempo que su significación sagrada. Para Auguet "los combates de gladiadores, antes incluso del fin de la república perdieron casi por completo su valor de rito, y podemos hablar ciertamente de secularización". ${ }^{6}$ A comienzos del Imperio, el munus ya estaba totalmente desacralizado. No obstante, aunque el munus perdió esos elementos, al mismo tiempo fue adquiriendo otros nuevos que lo convirtieron en un fenómeno extremadamente complejo. Así, por ejemplo, los munera conllevaban, cada vez más, toda una serie de relaciones sociales complejas: organización, producción, presentación del evento,

6 Auguet 1972, 22. 
etc. De hecho, los munera articulaban la sociedad, la política y la cultura, y aportaban la forma y el fondo para la expresión y representación de los valores romanos.

Los ciudadanos romanos disfrutaban de juegos, en sus distintas modalidades, durante una gran parte del año. En la República se celebraban, en honor de algunas divinidades, cada año y de manera oficial, juegos y espectáculos públicos (ludi publici), ${ }^{7}$ especialmente, los circenses, ${ }^{8} \operatorname{los}$ munera et venationes ${ }^{9} \mathrm{y}$ los scaenici. ${ }^{10}$ Los organizaban los magistrados anuales: pretores y ediles, principalmente. Para la organización y realización de dichos eventos, los magistrados recibían del erario público una cantidad fija, aunque a todas luces insuficiente, por lo que tenían que asumir muchos gastos de su propio bolsillo lo que, en ocasiones, les llevaba a la ruina; sin embargo, se entregaban a ello con verdadera ilusión, sobre todo, por el deseo de conseguir fama y popularidad entre sus conciudadanos. La organización y la propaganda de la celebración de unos juegos fastuosos les servían para conseguir votos, fama y popularidad, lo que les llevaría a obtener la magistratura a la que aspiraban. A fines de la República los ludi Romani se convirtieron en una importante arma electoral, fenómeno estrechamente ligado con el nacimiento del evergetismo en Roma. ${ }^{11}$ Los romanos, cuando daban un munus en alguno de los territorios conquistados, lo ofrecían también como un instrumento de romanización. ${ }^{12}$

Poco a poco el munus fue saliendo del ámbito del funeral privado y comenzó a convertirse en un espectáculo público. Así, en el 105 a.C., el estado dio, por vez primera, un munus. Los cónsules del año, P. Rutilio Rufo y Cn. Malio Máximo, ofrecieron un munus sin razón alguna, sin pretexto de festividad religiosa, inaugurando con él una serie de espectáculos públicos. ${ }^{13}$ La intención del estado era: "fomentar el coraje viril, promover el desprecio por la vida, desarrollar el gusto por el entrenamiento militar y contrarrestar las costumbres licenciosas griegas, que empezaban a propagarse y que eran calificadas por los mayores de frívolas y funestas". ${ }^{14}$

Debido a este nuevo status del munus, se vio la necesidad de regularlo. Así, a partir de entonces, los munera se rigieron por las leges gladiatoriae, según las cuales la superintendencia de todos los juegos se asignaba: en Italia, a los praefecti alimentorum, en las provincias con procurador, al propio procurator, en las provincias consulares,

7 Sobre ludi romani, cf. FriedläNder 1920; Friedländer 1967, 5-257; PigAnOL 1923; VEYNE 1976; Domergue - Landes - Pailler 1990; Clavel-Lévêque 1984; Weber 1986; Mancioli 1987; Bernstein 1998; Futrell 2007; Kyle 2007; Ángela 2007.

8 Cf. Cameron 1976; Humphrey 1986; Landes 1990; Nogales 2000; Nogales - Sánchez Palencia 2002.

9 Cf. Lafaye 1896, vol. 2, 1563-1600; Schneider 1895, 760 ss; Grant 1967; Briceño 1986; Ville 1981; Kohn 2000; vid. también, Pastor 2002, 485-499; Shadrake 2005; Wiedmann 1992; MeiJer 2006; Junkelmann 2008; Teyssier 2009; Cagical 2010; Luca Gregori 2011; para las venationes, cf. Darember SAglio 1896, vol. 2; Briceño 1986, 51-57; MANCiOLI 1987, 66-68.

10 Cf. Dupont 1985; Beacham 1991; Landes 1992; Ciancio - Pisani 1994-1996; vid. también, Pociña $1976,435-442$.

11 Cf. PAStor 2008, 395-405; PASTOR 2011, 213-230.

12 Gunderson 1996, 113-151; ClaVEL-LÉvÊQue 1986, 2405.

13 Val. Max. 2.3.2. Cf. PAstor MuÑoz - PAstor Andrés 2009, 176, donde señalan que la organización del munus del 105 a.C. significó el reconocimiento oficial del munus como espectáculo público.

14 Briceño 1986, 21. Vid. también: Vismara 1999a, 23 ss; Vismara 1999 b, 75 ss. 
a los legati pro praetore y, en Roma, al praefectus urbis. Las leges gladiatoriae variaban de ciudad en ciudad, pero en todas se imponía el principio común de que ningún munus podía celebrarse sin el consentimiento de las autoridades civiles. ${ }^{15}$ (Fig. 2) Esto evidencia el interés del estado por controlar una actividad muy importante política y económicamente, puesto que los impuestos que la gravaban le generaban pingües beneficios.

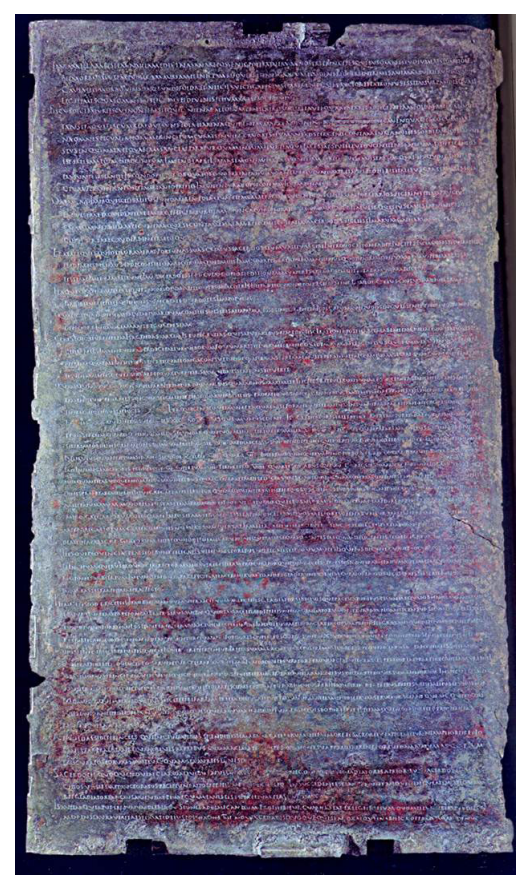

Fig. 2. Tabla de bronce encontrada en Italica. Museo Arqueológico Nacional de Madrid.

Pese a todo, el prístino motivo fúnebre se resistía a desaparecer y, en ocasiones, se utilizaba como excusa para ofrecer un munus, como hicieron, entre otros, César, Cecilio Metelo, Escribonio Curión, el propio Augusto y Marco Aurelio. ${ }^{16}$ En el siglo I a.C., los munera se habían convertido ya en un gran entretenimiento público y en un poderoso instrumento político para atraer votantes. ${ }^{17}$ Hasta tal punto era así que los políticos competían por ver quién ofrecía el munus más espectacular. Ofrecer munera era el medio por el cual mejor percibía el pueblo la capacidad de un político:

15 JACOBELli 2003,19.

16 Suet., Caesar 26; Cic., Ad Atticum 2.1; Flav. Jos., Guerras judias 1.149-154; Plin., NH, 36.117-120; Dio Cas., 55.8.5; Suet., Tiberius 7.1; Suet., Claudius 2.2; Hist. Aug. Marcus 8.2. El munus de César en memoria de su fallecida hija Julia sentó precedente, pues nunca antes se había dado un munus para honrar a una mujer. No obstante, parece que desde ese momento se fue generalizando, hasta convertirse en algo normal, pues Plinio el Joven menciona un munus ofrecido en honor de una mujer difunta (Epistulae 6.34).

17 Sobre las ventajas políticas de organizar ludi, cf. principalmente, PASTOR 2011, 213-230; vid. también, FRANKLIN 1997, 434-447. 
"si es capaz de gestionar buenos munera es capaz de gestionar bien el estado" era el razonamiento de la plebe. ${ }^{18}$ De hecho, el candidato que no ofrecía juegos no tenía posibilidades de salir elegido. ${ }^{19}$

Un claro ejemplo fueron los munera dados por César, de gran coste económico, aunque no hay que pensar que César despilfarraba el dinero, sino que lo invertía para obtener el apoyo popular. En cualquier caso César no gastó ni un solo sestercio de más en sus munera, pues ordenaba siempre conceder la missio (indulto) a los gladiadores famosos y caros que caían derrotados..$^{20}$ Esta costumbre fue luego adoptada también por Augusto al prohibir los munera sine missione, que implicaban la muerte forzosa del perdedor, ${ }^{21}$ como luego veremos. A finales de la República, una carrera política requería enormes cantidades de dinero, por lo que los aspirantes se endeudaban para poder financiar sus candidaturas. Muchos, incapaces de hacer frente a los gastos, se veían obligados a pedir dinero a amigos o familiares. ${ }^{22}$ En cualquier caso, el gasto de los políticos en los munera era ruinoso. Esto se debía, sobre todo, a que, como actos de ciudadanos privados que eran, el estado no financiaba nada del espectáculo, sino que todo el costo económico del munus recaía sobre el editor.

El derroche llegó a tal extremo que Cicerón pensaba que ofrecer munera al pueblo no era más que un soborno para comprar su voto ${ }^{23}$ en lugar de la pretendida generosidad que los editores pretendían mostrar. ${ }^{24}$ Para tratar de controlar estos excesos, el Senado hizo intentos por ejercer algún control sobre los munera, limitándolos en ciertos aspectos, pero solo se logró un control parcial; será con Augusto cuando se controlen mediante leyes.

El ambiente político de finales de la República se fue volviendo cada vez más violento, ya que cada candidato tenía su propia "guardia de gladiadores", que le servía de escolta. El Senado, lógicamente, se alarmó por este fenómeno y decidió ponerle límites. Por ejemplo, César, para los munera que ofreció en 62 a.C., contrató a un ingente número de gladiadores, que, como propiedad temporal suya, entraron con él dentro de las murallas de Roma, donde se debía celebrar el espectáculo. El riesgo era evidente. En consecuencia, el Senado actuó, poniendo un límite al número de gladiadores que podían introducirse en la urbe ${ }^{25}$ De este modo, el número máximo de gla-

18 Dio Cas., 37.8: "El gran Pompeyo y Julio César hicieron una competición de la organización de los juegos. El primero, en cinco días de venationes, hizo matar 500 leones, mientras que con César se vieron morir 400 en un solo día. César quiso mostrarse generoso a toda costa. En una ocasión, por hacer combatir a 320 parejas de gladiadores en la arena, se endeudó por millones de sestercios". Vid. WiEDMANN 1992, 6 ss.

19 Cic., Pro Murena 37-39.

20 Suet., Caesar 26.2-3: [César, en su triunfo del 46 a. C.] gladiatores notos, sicubi infestis spectatoribus dimicarent, vi rapiendos reservandosque mandabat.

21 En los munera sine missione los vencidos siempre eran muertos por el vencedor. No se dejaba al público la opción de decidir si salvar la vida del vencido, o no. Liv., 41.20.12; Suet., Augustus, 45.3; Nero, 4.3; Petron., Satyricon 45; Flor., 2.8.14; CIL X, 6012; cf. RoBERT 1940, 258-261.

22 Polib., Historiae 31.28.5-6.

23 Cic., De Officiis 2.55-56.

24 Cf. principalmente, PASTOR 2008, 395-405.

25 Suet., Caesar 10.2: [Durante su mandato como edil] Adiecit insuper Caesar etiam gladiatorium munus, sed aliquanto paucioribus quam destinaverat paribus; nam cum multiplici undique familia conparata inimicos exterruisset, cautum est de numero gladiatorum, quo ne maiorem cuiquam habere Romae liceret. 
diadores que por ley podía poseer un ciudadano fue disminuyendo con el tiempo: 300 parejas al final de la República, 100 en tiempos de Augusto y 70 en época de Tiberio.

En el 49 a.C., cuando César se disponía a invadir Italia, volvieron a surgir temores acerca de los gladiadores que poseía; César era el propietario del ludus de Capua, y se temía que cuando llegara a esa ciudad incorporaría a sus tropas a los 1.000 gladiadores que tenía en su ludus, una ayuda considerable para la guerra civil. Evidentemente, Pompeyo tomó sus precauciones, diseminando a los gladiadores del ludus de Capua. ${ }^{26}$ Una medida similar se adoptó durante la crisis de finales de la República, tras el asesinato de César, cuando el Senado decidió sacar de Roma a todos los gladiadores, para evitar que algún conspirador los incorporarse a sus filas e intentase hacerse con el control de la ciudad. ${ }^{27}$

Aparte del atractivo propio del combate, los munera eran tan populares porque ofrecían a la audiencia la oportunidad de expresar a los políticos y clase dirigente, su opinión sobre los asuntos de actualidad. ${ }^{28}$ La utilización de los ludi para celebrar y adornar los logros políticos y militares se acentuó a partir del Imperio; por ejemplo, se aumentaron los días de juegos (por el cumpleaños del emperador, por el aniversario de su proclamación, por el nacimiento de sus hijos, etc.). ${ }^{29} \mathrm{Y}$ se realizaron cambios que afectaron a otros ludi (munera, circenses).

Como el Senado estaba a las órdenes del emperador, los senadores dejaron de competir por organizar munera y perdieron su interés por organizarlos, sobre todo, por el enorme coste de los juegos. Por ello, Augusto, sabedor de que los munera eran la pasión del pueblo de Roma, integró los ludi entre las actividades propias de su cargo y cargó con su responsabilidad. En este sentido, comenzó a ofrecer munera organizados por el estado y, para que su coste no fuese excesivo, creó los ludi imperiales y autorizó la construcción de anfiteatros permanentes en Roma. Sirvan como ejemplo los ludi (escuelas de gladiadores) de Pompeya (Fig. 3) y el recientemente encontrado en Carnuntum (Austria). Así, la organización de cada munus imperial le salía poco costosa y muy rentable, puesto que combatían sus propios gladiadores y en su propio anfiteatro. Ya no tenía que recurrir a los lanistae para comprar gladiadores. ${ }^{30}$ Además, Augusto dictó toda una serie de normas que reglamentaron detalladamente la gladiatura. ${ }^{31}$ Nada escapaba a su control, ni siquiera la distribución de los espectadores en las gradas. Igualmente, durante el Imperio, los anfiteatros se extendieron aún más a lo largo de todas las tierras gobernadas por Roma; la romanización de los pueblos conquistados tenía lugar mediante varios procesos, uno de los cuales fue lograr que el espectáculo nacional de Roma (munus) fuese el espectáculo favorito de todos los

26 Cic., Ad Atticum 7.14.

27 Salust., Coniuratione Catilinae 30.

28 Cic., Pro Sestio 106: etenim tribus locis significari maxime de (re publica) populi Romani iudicium ac voluntas potest, contione, comitiis, ludorum gladiatorumque consessu.

29 Tac., Historiae 2.95: Quin et natalem Vitellii diem Caecina ac Valens editis tota urbe vicatim gladiatoribus celebravere, ingenti paratu et ante illum diem insolito. En buena medida los emperadores usaron los munera como un instrumento político para mejorar su imagen pública. Vid. NEwBOLD 1975, 604 ss.

30 Hasta entonces, los munera se celebraban en instalaciones temporales provisionales, montadas en el forum o en el campus martius o en el circus maximus.

31 Junkelmann 2000, 35 ss. 
habitantes del Imperio. En consecuencia, el munus se convirtió en el espectáculo por antonomasia de Roma y de las provincias.

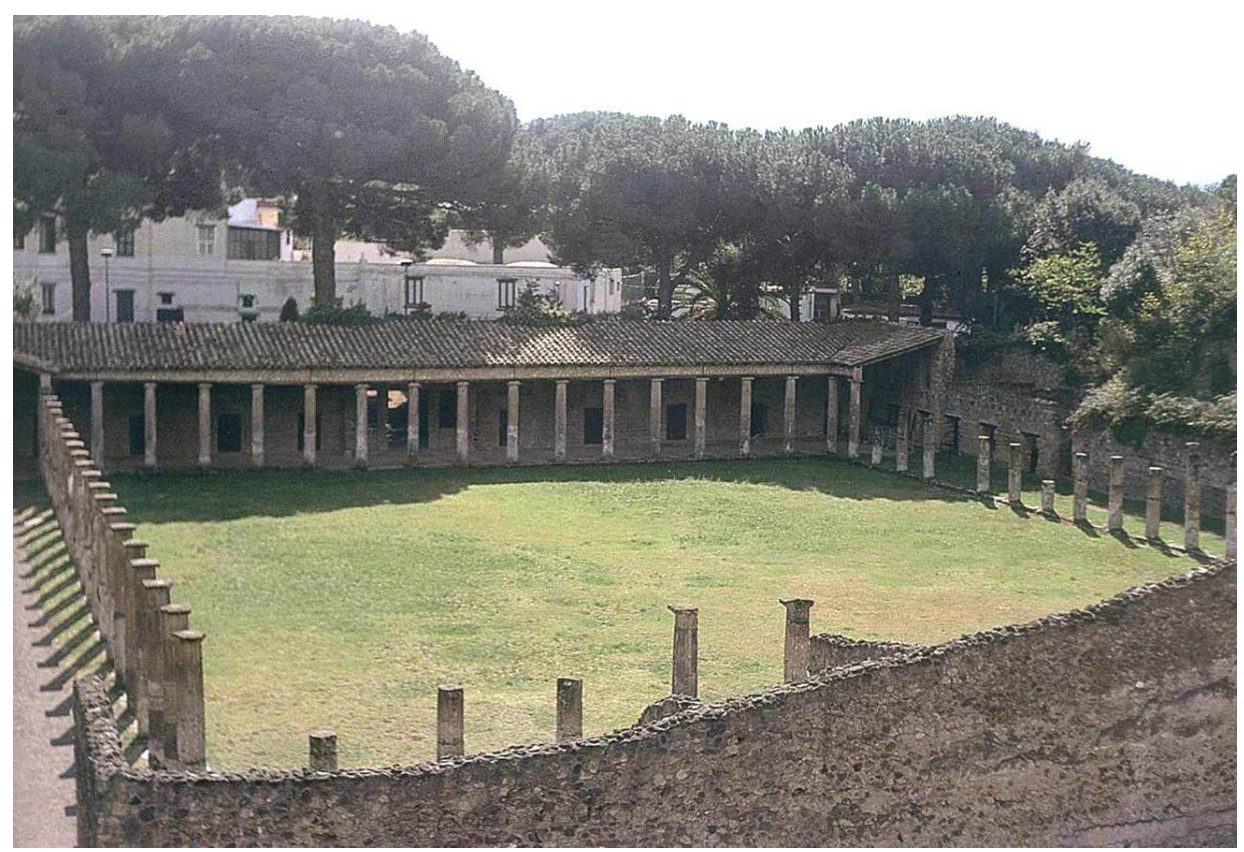

Fig. 3. Ludus de Pompeya. Peristilo, casernae y almacenes.

Suetonio nos informa, con bastante detalle, de los aspectos de los munera que se vieron afectados por las reformas de Augusto: ${ }^{32}$

[43] "Aventajó a todos sus predecesores en él número, variedad y magnificencia de los espectáculos. Dice él mismo que organizó juegos públicos cuatro veces en su nombre y veinte tres en nombre de otros magistrados que se hallaban ausentes o carecían de recursos suficientes. Los ofreció, a veces, incluso en los barrios de la ciudad, sobre diversos escenarios y con actores de varios países. Presentó juegos de gladiadores no solo en el Foro y en el Anfiteatro, sino también en el Circo y en los Cercados ${ }^{33}$ a veces exhibía solo combates con fieras salvajes. Ofreció también combates de atletismo en el campo de Marte, en donde hizo construir bancos de madera, e incluso una batalla naval en una piscina excavada junto al Tíber, donde hoy se yergue el bosque de los Césares. ... Exhibía en el Circo a aurigas, corredores, y cazadores de fieras, a los que reclutaba, a veces, de entre los jóvenes de la más alta nobleza. También exhibió con mucha frecuencia los Juegos Troyanos en los que participaban muchachos de diferentes edades, pues juzgaba que era una costumbre bella y antigua dar así a conocer la índole de las

32 Suet., Augustus 43-45.

33 Se trata de los llamados "Cercados de Julia" en el campo de Marte donde se celebraban las elecciones. El nombre deriva de las "vallas" (saepta) levantadas para separar las distintas tribus en las votaciones. 
estirpes establecidas. Le regaló un collar [torque] de oro a C. Nonio Asprenas, herido al caer en una de estas luchas, y le autorizó a él y a sus descendientes a llevar el nombre de Torquatus. ${ }^{34}$ Más tarde dejó de celebrar estos Juegos a consecuencia de las amargas e insidiosas quejas que dio en el Senado el senador Asinio Polión, cuyo sobrino Esernino se había roto una pierna. En las representaciones escénicas y combates de gladiadores se valió a veces de caballeros romanos, pero eso fue antes de que un acuerdo del Senado lo prohibiera. A partir de entonces dejó de utilizar los miembros de este estamento, a excepción de un joven de noble linaje llamado Lucio, a quien exhibió como una curiosidad, pues no llegaba a tener dos pies de estatura, pesaba diecisiete libras y su voz era de una potencia extraordinaria...".

[44] "Subsanó y reglamentó la forma hasta entonces promiscua e indisciplinada con que se asistía a los espectáculos. Le indujo a ello la afrenta inferida a un senador, al cual, durante unos juegos muy concurridos celebrados en Puteoli, nadie hizo sitio a causa de la aglomeración de espectadores. En consecuencia, hizo que el Senado promulgara un decreto por el que se disponía que siempre que en algún lugar se celebraran espectáculos de carácter oficial debían reservarse las primeras filas de asientos para los senadores y prohibió que los representantes de los pueblos libres o aliados se sentaran en Roma en la orquesta, pues se enteró que figuraban, a veces, entre ellos simple libertos. Separó los soldados del pueblo. Asignó a los plebeyos que estaban casados asientos especiales y reservó a los muchachos que llevaban ya la toga praetexta un sector exclusivamente para ellos y el contiguo a sus pedagogos; prohibió terminantemente que ninguna persona vestida de negro se sentase en el centro de la platea. No permitió a las mujeres presenciar los combates de gladiadores a no ser desde las gradas más altas y solas, a pesar de que era ya una costumbre habitual que pudieran presenciar estos combates confundidas con los hombres. Destinó a las Vestales un lugar aparte frente a la tribuna del pretor. Excluyó con tanto rigor a todas las mujeres de las competiciones de atletismo que en los juegos que ofreció al tomar posesión del Pontificado Máximo cambió para el día siguiente la exhibición de una pareja de púgiles, a pesar de que el pueblo la reclamaba con insistencia, e hizo público "que no le parecía bien que las mujeres fuesen al teatro antes de la hora quinta".

[45] “.... prohibió que los combates de gladiadores se prolongasen hasta la muerte [gladiatores sine missione edi prohibuit]; restringió a los magistrados el derecho que una antigua ley les atribuía de azotar a los actores en todo tiempo y lugar y lo limitó a los días que se celebraban los juegos y al recinto de los teatros. Mas ello no fue obstáculo para que exigiera siempre una severísima disciplina tanto en las competiciones de atletismo como en los combates de gladiadores. En cuanto a los actores refrenó sus costumbres licenciosas con extrema severidad, así, a Estefanión, especializado en representar obras de ambiente romano, lo hizo azotar en tres teatros diferentes y luego lo desterró, porque supo que se hacía servir por una matrona romana con los cabellos cortados al rape en forma que parecía un muchacho; al bufón Hilas, por quejas del pretor, le mandó azotar en el atrio de su propia casa, donde todos pudieron verlo; y desterró de Roma e Italia al cómico Pilades, por haber señalado con el dedo, mostrándolo al público, a un espectador que lo silbaba”.

34 El nombre Torquatus se relaciona con la palabra tor = "collar de oro", "torques", que usaban los pueblos indoeuropeos. 
Una de sus medidas (en 22 a.C.) fue la de encargar a los praetores la tarea de organizar en las provincias munera imperiales oficiales, que tenían lugar en diciembre. Con el paso del tiempo se fueron añadiendo más días de juegos. El calendario de Furio Dionisio Filócalo (del año 354), señala 10 días de munera ordinarios y oficiales $(2,4,5,6,8,19,20,21,23$ y 24 de diciembre). Pero, aparte de los ordinarios, estaban los extraordinarios, es decir, aquellos que se organizaban por cualquier motivo no previsto: celebración de una victoria militar, por petición del emperador, bodas y nacimientos de la familia imperial, etc. ${ }^{35}$ Por tanto, mientras que en Roma los días de munera extraordinarios eran infinitamente superiores a los días de munera ordinarios, en las ciudades de las provincias parece que lo predominante eran los munera ordinarios, ya que ahí no ocurrían tantas circunstancias extraordinarias que celebrar como en Roma. ${ }^{36}$

Augusto estableció, pues, un mínimo de munera ordinarios para asegurarse de que en todas las partes del Imperio, todas las personas pudieran ver al año una cantidad mínima de munera, para que así se aficionaran, adoptaran este espectáculo como su favorito y pudieran sentirse parte del mundo romano. ${ }^{37}$ Augusto advirtió que el munus, el espectáculo gladiatorio de Roma, era un instrumento esencial para lograr la integración de todos los pueblos en el Imperio. Un ciudadano al que le gustaban los munera, verdaderamente se sentía romano, una ciudad que ofrecía munera era realmente una ciudad romana.

Los pretores provinciales solo podían ofrecer dos munera al año y solo podían presentar un máximo de 60 gladiadores en cada uno. Para su organización cada pretor recibía una cierta cantidad de fondos públicos, la misma para todos y estos no podían añadir sumas propias, con objeto de que ningún pretor pudiese ofrecer mejores munera que el resto, ${ }^{38}$ así ninguno destacaba y ninguno podía hacer sombra a los espectáculos ofrecidos por el emperador. ${ }^{39}$ Tales restricciones muestran también que Augusto deseaba contener el gasto en los munera provinciales. Tiberio continuó con estas limitaciones y Claudio llegó incluso a prohibir a los pretores dar los espectáculos gladiatorios de costumbre, ${ }^{40}$ con la intención de poder volver a la normalidad tras los excesos de su sobrino Calígula, que ofreció munera de manera descontrolada hasta esquilmar las arcas del estado.

35 Cic., Ad Fam. 7.1; In Vatinium 15.37; Pro Sull. 19.54; Plin., Epist. 1.8.9; Suet., Caligula 27; Tac., Hist. 2.95; Hor., Sat. 2.3.84. El gusto de los romanos por los juegos era insaciable y se reflejó en el continuo aumento del número de días festivos; si con Augusto disfrutaban de 77 días festivos al año, para el siglo IV tenían 177. Vid. CAMERON 1976, 175.

36 FriedLÄNDER 1965, vol.2, 11.

37 Cf. Ceballos 2003, 63, piensa que, por fuerza, debía haber al año más de esos 10 munera que señala el calendario, pues "la construcción de un anfiteatro de piedra superaba en el caso más modesto el millón de sestercios". También, KondoleON 1999, 321.

38 Dio. Cas., 54.1.4. "De manera extraordinaria se permitía a algún ciudadano pagar una editio muneris, pero siempre se debía especificar que el acto se hacía en nombre del emperador. Evidentemente esta actividad no ponía en peligro al emperador, pues por muy rico que pudiese ser un individuo nunca podía competir con lo ofrecido por el princeps". Cf. Lussana 1950, 123; RizAKIS 1984, 533-542; RizAKIs 1990, 201-208.

39 Dio. Cas., 54.2.3-4.

40 Dio. Cas., 60.5. 
Evidentemente, Augusto había reconocido el valor de las relaciones públicas que se establecían en los munera, y por eso se aseguró ser el único que ofrecía los mejores. Y de hecho, los espectáculos de Augusto fueron los más grandiosos que se habían visto hasta entonces..$^{41}$ Cada uno de los munera ofrecido por Augusto presentaba unos 1.250 gladiadores en la arena (diez veces más que los de los pretores en las provincias) y 135 animales. A todas luces, eran espectáculos que solo un emperador podía hacer realidad.

Sin embargo, pese a todas sus innovaciones, la conexión fúnebre seguía estando presente; así, una de sus primeras acciones públicas, antes de convertirse en emperador, fue establecer juegos en honor de Julio César, su padre adoptivo. El culto de Julio deificado (divus Iulius) fue desarrollándose con el tiempo, completándose en el 29 a.C., año en que le dedicó un templo en el forum. La consagración del templo se celebró con toda una serie de espectáculos, munera incluidos. ${ }^{42}$ De hecho, ofrecer munera para celebrar la consagración de templos se convirtió en una costumbre imperial, una de esas circunstancias excepcionales por las que se daban munera. Así, en el 2 a.C., los hijos de Agripa ofrecieron munera como parte de las celebraciones para dedicar el forum de Augusto y el templo a Mars Ultor. ${ }^{43}$

Evidentemente, Augusto tuvo que gastar cantidades enormes de dinero para dar todos esos munera, pero durante el Imperio la mentalidad había cambiado y que un espectáculo fuese muy caro ya no era tachado de derroche, como había hecho Cicerón, sino que ahora se consideraba un mérito. Opinaban que un espectáculo imperial, para que fuese bueno, digno del emperador que lo daba, debía ser caro, porque el lujo y la fastuosidad debían ser lo que caracterizara al Imperio. ${ }^{44}$ Por tanto, no puede extrañarnos, en absoluto, que Augusto no reparase en gastos, y la idea de que el fasto y el lujo eran una de las señas de identidad del Imperio se mantuvo a lo largo del tiempo como mostrarían después Vitelio, Heliogábalo y otros muchos emperadores, famosos por su desmesura en el lujo con el que dieron juegos. ${ }^{45}$

El munus era también un instrumento de control social evidente, pues durante el tiempo que el pueblo pasaba en el anfiteatro no estaba conspirando contra el poder $\mathrm{y}$, además, estaba controlado. Esto lo comprendió perfectamente Augusto, por lo que consideró como una obligación ofrecer atenciones al público y distribuciones gratuitas de comida. Así lo hacía más atractivo para la plebe y así todos acudían a esa especie de "cárcel de oro". Mediante munera que contentaban al pueblo, el emperador tenía la posibilidad de controlar a la numerosa población romana, potencialmente

41 Augusto, Res Gestae 22: Ter munus gladiatorium dedi meo nomine et quinquens filiorum meorum aut nepotum nomine; quibus muneribus depugnaverunt hominum circiter decem millia. ... Venationes bestiarum Africanarum meo nómine aut filiorum meorum et nepotum in circo aut in foro aut in amphitheatris populo dedi sexiens et viciens, quibus confecta sunt bestiarum circiter tria millia et quingentae.

42 Dio. Cas., 51.22.

43 Dio. Cas., 55.10.

44 Dio. Cas., 52.30.1: [consejos de Mecenas]: “Adorna esta capital [Roma] con enorme desprecio del costo y hazla magnífica con festivales de toda clase. Porque es correcto que nosotros que gobernamos a muchos pueblos superemos a todos los hombres en todas las cosas, y excelencia de este tipo tiende también en cierto modo a inspirar a nuestros aliados respeto hacia nosotros, y terror a nuestros enemigos".

45 Tac., Historiae 2.94: [en el año 69, Vitelio] ipse sola perdendi cura stabula aurigis extruere, circum gladiatorum ferarumque spectaculis opplere, tamquam in summa abundantia pecuniae inludere. 
peligrosa por estar desocupada y por vivir cerca del centro del poder. ${ }^{46}$ De esa manera, el pueblo ya no tenía tiempo para pensar en su situación vital, y en lo que sería de ellos y de sus hijos al día siguiente; estaban a gusto sentados en la grada viendo el espectáculo, y con la barriga llena, deseando solo poder estar haciendo lo mismo al día siguiente, y que los dioses dieran larga vida al emperador que hacía todo eso posible. ${ }^{47}$ Esta necesidad política del munus fue admitida por todos los analistas, incluso por Frontón, tutor de Marco Aurelio. ${ }^{48}$

Como apuntábamos antes, durante la República, las gradas de los anfiteatros eran usadas con frecuencia por el pueblo para expresar su opinión a los dirigentes. Esto se acentuó en el Imperio debido a la concentración de todo el poder en una sola persona, que presidía los juegos. Así, el munus ofrecía al pueblo el atractivo extra de tener la posibilidad de expresar directamente a la cabeza visible del estado su parecer con respecto a cualquier asunto que le interesara. La multitud que se concentraba en los espacios para juegos (50.000 en el Coliseo, o casi 250.000 en el Circus Maximus) gritaba al emperador sus quejas y exigencias y el emperador no tenía más remedio que escucharlas. ${ }^{49}$ Sin duda las expresiones populares en las gradas del Coliseo serían muy similares. ${ }^{50}$ No solo es llamativo que se permitiese expresarse libremente a los espectadores, sino mucho más, que el propio el emperador estuviese obligado a responder, como lo había hecho Claudio. ${ }^{51}$ Un emperador que no respondía quedaba mal, como que no merecía el cargo. El hecho mismo de responder era considerado como muestra de la grandeza del emperador, que era tan magnífico que incluso se dignaba a contestar al pueblo. Además, según fuese la naturaleza de la respuesta, ésta podía mostrar el carácter, el ingenio y el liderazgo del emperador, cualidades todas que se esperaba que poseyera. Este diálogo era fundamental para crear, o destruir, la imagen pública del emperador, porque no ser capaz de responder adecuadamente a un plebeyo, ante la presencia de todo el pueblo, daba una imagen patética. ${ }^{52}$

46 Sobre la plebs, cf. principalmente, CARCOPINO 1968, 20 ss; FINLEY 1973, 104 ss; HopkINs 1978,24 ss; Evans 1980, 137 ss; White 1970, 345 ss.

47 Cf. GutTamann 1978, 149 y 153.

48 Fronto, Principia Historiae 20: Pacis artibus vix quisquam Traiano ad populum, nescio si qui adaeque, acceptior fuerit. Ipsa haec cum prioris vitae nonnullis detrectationibus lacessunt. Ex summa civilis scientiae ratione sumpta videntur, ne histrionum quidem ceterorumque scaenae aut circi aut harenae artificum indiligentem principem fuisse, ut qui sciret populum Romanum duabus praecipue rebus, annona et spectaculis, teneri; imperium non minus ludicreis quam serieis probari atque maiore damno seria, graviore invidia ludicra neglegi; minus acribus stimulis congiaria quam spectacula expeti; congiarieis frumentariam modo plebem singillatim placari ac nominatim, spectaculis universum interdum esse...

49 Dio. Cas., 76.4. En el 195, Dión Casio asistía a un espectáculo en el circo cuando los espectadores, tras cantar al unísono el habitual saludo "Roma Inmortal”, comenzaron a gritar a coro, como una sola voz, ¿Hasta cuando vamos a estar en guerra?”. Dión quedó impresionado de que tantos miles de personas pudieran gritar al unísono, "como un coro bien entrenado".

50 Esta licencia los autores latinos la llamaron licentia theatralis. Cf. BoLlinger 1969, 10-22.

51 Suet., Claudius 21.

52 Suet., Domitianus 10.3: Patrem familias, quod Thraecem murmilloni parem, munerario imparem dixerat, detractum spectaculis in harenam canibus obiecit cum hoc título: 'Impie locutus parmularius. Esto repercutió en la mala imagen de este emperador. Sus contemporáneos le consideraban un loco y un tirano; vid. Plinio el Joven, Panegyricus 33. 
Así, el anfiteatro se convirtió en uno de los pocos lugares en que el pueblo podía expresar su opinión al emperador, dado que ambas partes estaban sentadas en un mismo espacio cerrado, y que debían estar ahí por varias horas, el emperador se mostraba abierto a ese diálogo. Era importante para él y para su popularidad, ver y ser visto disfrutando junto con el pueblo del espectáculo, y mostrarse presto a escuchar, al menos, sus peticiones. Plinio el Joven celebra tales ocasiones como oportunidades que tiene el emperador de mejorar su imagen pública mediante la estrategia de disfrutar del espectáculo junto con el resto de romanos. ${ }^{53}$ Hubo, incluso, emperadores que llevaron esa táctica de mostrarse próximos al pueblo durante los munera hasta extremos inusitados, como Claudio, que durante los juegos daba una imagen como espectador decididamente plebeya, importándole poco mantener una apariencia de dignidad imperial. Incluso daba explícitamente el poder al pueblo de Roma, para que eligiese a los contendientes. ${ }^{54}$

En Roma, había algunos que también se daban cuenta de que los munera se usaban para conseguir "tranquilidad social", como si fuesen una especie de soborno: "el emperador te entretiene dándote juegos, no te quejes luego de otras cosas que haga y que no te agraden". Ese parecía ser el razonamiento por el cual los emperadores se guiaban. A cambio de juegos, esperaban que el pueblo se conformase con las condiciones de vida que tenía, cediendo así parte de su libertad. Esta actitud, criticable en ambas partes, es la que denuncia Juvenal en sus famosos versos panem et circenses. ${ }^{55}$ Pero esto no era nada nuevo en su época, pues el utilizar los munera como soborno ya lo hicieron los políticos durante la República y lo siguieron haciendo los emperadores durante el Imperio. ${ }^{56}$

Pero volvamos, de nuevo, al programa de reformas efectuadas por Augusto que afectaron plenamente a los munera, según se desprenden del texto de Suetonio, que vimos antes. ${ }^{57}$ Con las normas de Augusto se produjo una mejora en el reglamento que hasta entonces había regido la gladiatura. Lo que antes había sido un listado de

53 Plinio el Joven, Panegyricus 51: ... [a Trajano] hic immensum latus Circi templorum pulchritudinem provocat, digna populo victore gentium sedes, nec minus ipsa visenda, quam quae ex illa spectabuntur: visenda autem cum cetera specie, tum quod aequatus plebis ac principis locus. Siquidem per omne spatium una facies, omnia continua et paria, nec magis proprius spectanti Caesari suggestus, quam propria, quae spectet. Licebit ergo civibus tuis invicem contueri: dabitur, non cubiculum principis, sed ipsum principem cernere: in publico, in populo sedentem; vid. también, Tert., De Spectaculis 25:...nisi videri et videre. El anfiteatro, como el circo o el teatro, era un lugar al que se iba a ver, pero, sobre todo, a ser visto. Cf. ZACCARIA 1994, 98.

54 Suet., Claudius 21.4-5: Gladiatoria munera plurifariam ac multiplicia exhibuit ... Nec ullo spectaculi genere communior aut remissior erat, adeo ut oblatos victoribus aureos prolata sinistra pariter cum vulgo voce digitisque numeraret ac saepe hortando rogandoque ad hilaritatem homines provocaret, dominos identidem appellans, immixtis interdum frigidis et arcessitis iocis; qualis est ut cum Palumbum postulantibus daturum se promisit, si captus esset. Cf. CORBEILl 2002, 183 ss.

55 Juv., Sat. 10.77-81: iam pridem, ex quo suffragia nulli vendimus, effudit curas; nam qui dabat olim imperium, fasces, legiones, omnia, nunc se continet atque duas tantum res anxius optat, panem et circenses.

56 Hist. Augus. Hadrianus 7.3-12: unde statim Hadrianus ad refellendam tristissimam de se opinionem, quod occidi passus esset uno tempore quattuor consulares, Romam venit, Dacia Turboni credita, titulo Aegyptiacae praefecturae, quo plus auctoritatis haberet, ornato, et ad comprimendam de se famam congiarium duplex praesens populo dedit, ternis iam per singulos aureis se absente divisis... gladiatorium munus per sex dies continuos exhibuit et mille feras natali suo edidit.

57 Ut supra, vid. nota 32. 
reglas, establecidas por el uso y la costumbre y transmitidas de forma visual y/u oral, pasó ahora a reunirse en un conjunto depurado de normas, sancionadas por el emperador y registradas por escrito, aunque solo de manera parcial. ${ }^{58} \mathrm{En}$ esencia, fue un esfuerzo por dar al munus gladiatorio unas reglas oficiales y más elaboradas.

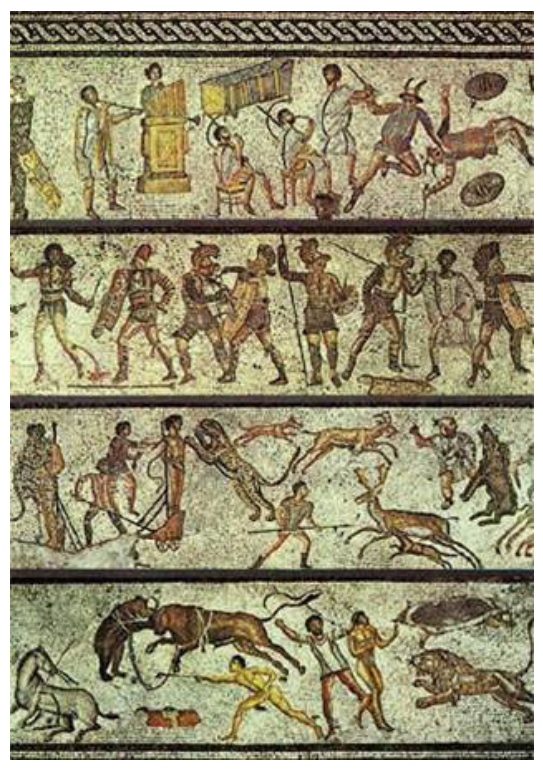

Fig. 4. Munus legitimum.Mosaico de Zliten (Libia).Museo Arqueológico de Trípoli.

Las principales medidas establecidas en la reforma de Augusto fueron: el establecimiento del munus legitimum, la desaparición de algunos tipos gladiatorios y su equipamiento, la prohibición de los munera sine missione, el calendario de los días que podían darse juegos y la ordenación de los espectadores en la grada y su vestimenta. Por lo que respecta al primero, Augusto implantó el munus legitimum (Fig. 4), es decir, la forma legítima (tal y como marcaba la ley) de ofrecer un espectáculo de anfiteatro. Estableció que el munus legitimum debía tener tres partes: ${ }^{59}$ la venatio, cacería de animales, o lucha con fieras (Fig. 5), que se celebraba por la mañana y duraba hasta el mediodía; ${ }^{60}$ los ludi meridiani o "juegos de mediodía", que eran las ejecuciones de los condenados a muerte por delitos más graves ${ }^{61}$-bien por la espada (ad gladium) o por medio de fieras (ad bestias)- y el munus propiamente dicho -los

58 Mar., Spect. 31: Lex erat, ad digitum posita concurrere parma.

59 El munus no estaba "completo", no era iustum et legitimum, si no incluía las tres partes. Los romanos diseñaron las tres partes del munus con la intención de atraer al mayor número posible de espectadores.

60 Cf. Regianni 1988, 148 ss; Beste 2001, 277 ss.

61 Suet., Claudius 24.6; Dio. Cas., 60.13.4; Sen., Epistulae 1.7.4; cf. Vismara 1987, 135; Vismara 1990, 253 ss.; el significado político e ideológico de las ejecuciones encontró en el anfiteatro una sede privilegiada, vid. Vismara 1999b, 75 ss. 
"combates de gladiadores"- (Fig. 6), que se celebraba por la tarde y eran la máxima atracción de la plebe romana que se concentraba en los anfiteatros.

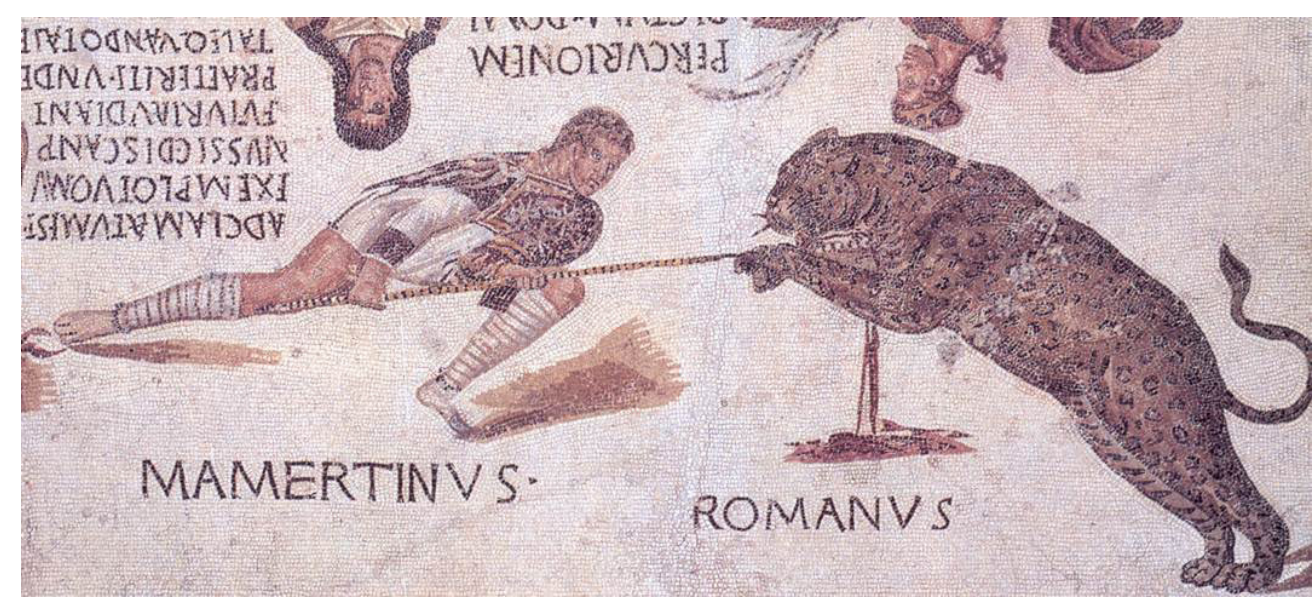

Fig. 5. Mosaicos con escenas de venationes.

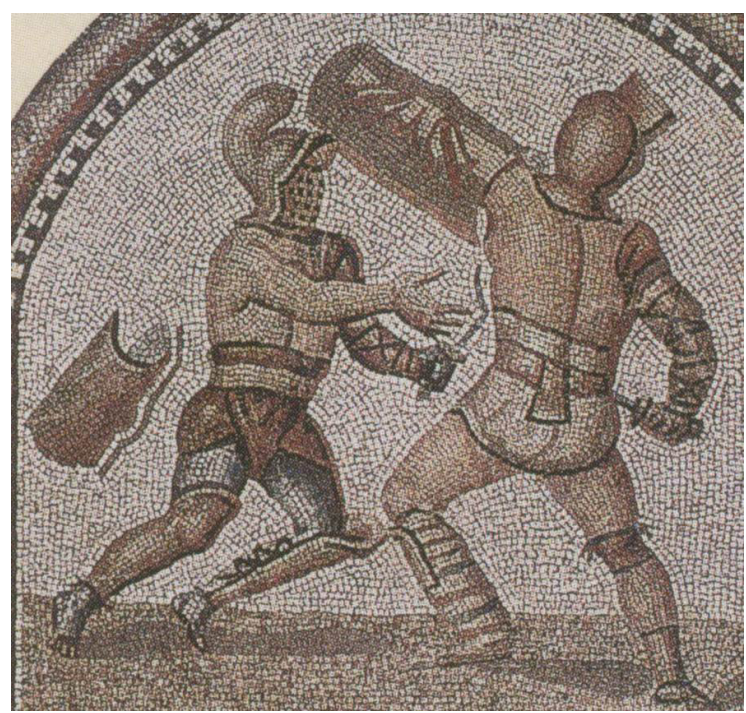

Fig. 6. Mosaico con lucha de gladiadores. Villa de Bad Kreuznach (Alemania).

Consecuencia de su reforma fue también la desaparición de algunos tipos de gladiadores, como el samnita (samnis), el galo (gallus), el tracio (traex) y el andabates. Sin embargo, surgieron otros con sus mismas armas: el sector, el oplomachus y el murmillo, (pero no vamos a detenernos en analizarlos aquí). ${ }^{62}$ La reforma del equi-

62 Sobre los distintos tipos de gladiadores y el momento de su aparición, cf. la bibliografía de la nota 9. 
pamiento afectó, principalmente, a las protecciones de la cabeza (Fig. 7). Antes de Augusto se podía luchar con casco o con yelmo, pero a partir de él, se estableció que los gladiadores solo podían luchar con yelmo, o sea, con el rostro cubierto, con la única excepción de los retiarii, que iban con la cabeza descubierta, como nos informa Suetonio al hablar de Claudio. ${ }^{63}$ La razón era igualar más los combates, ya que un yelmo, que cubre el rostro, limita mucho la respiración, por lo que no era justo que uno luchase con la cara cubierta contra otro que la llevara descubierta, que podía estar más tiempo combatiendo. ${ }^{64}$
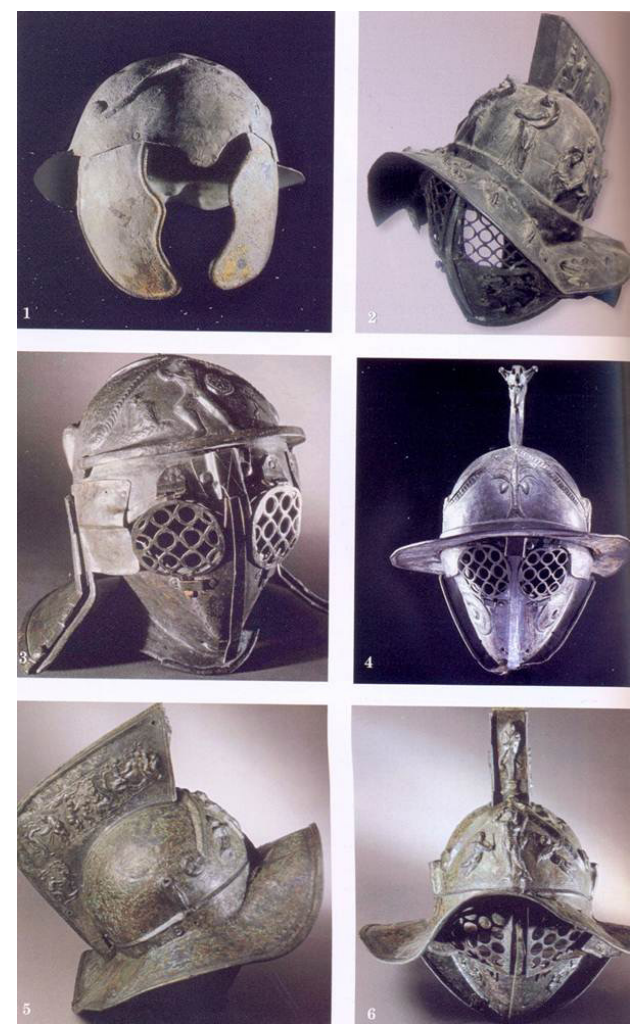

Fig. 7. Distintos tipos de cascos y yelmos. Museo de Budapest y Museo de Nápoles.

63 Suet., Claudius 45: "Las luchas de fieras y las del mediodía le gustaban tanto que no solo alargaba el espectáculo hasta el alba, sino que permanecía en su puesto hasta el mediodía cuando el populacho se iba a su casa a comer... En todos los combates de gladiadores ofrecidos por él o por algún otro, hacía degollar incluso a los que caían a tierra por casualidad, sobre todo, a los reciarios (que no llevaban casco) para observar su rostro mientras expiraban".

64 Sabemos por algunos contratos (Gayo, Inst. 3.146) que el editor debía pagar 80 sestercios (HS) por cada gladiador que actuaba y salía con vida y sin heridas, pero una cláusula especificaba que si el gladiador resultaba muerto (o mutilado en modo tal que ya no podía volver a luchar con el mismo nivel de destreza, debía pagar 4.000 sestercios (HS), además de los 80 anteriores. 
La reforma de Augusto supuso también la prohibición de los munera sine missio$n e .{ }^{65} \mathrm{El}$ término sine missione se aplicaba a dos modalidades de combate, por lo que creaba cierta confusión: a) que no existía la posibilidad de indulto (missio) para el vencido, que siempre era ejecutado por el vencedor; y b) el vencedor debía enfrentarse en un nuevo combate contra un nuevo gladiador (tertiarius o suppositicius). Por el cansancio, el vencedor del combate previo era quien tenía todas las posibilidades de perder y, por tanto, de morir. Así, con esta segunda modalidad, de todos los combates, al final solo sobrevivía un gladiador, mientras que con la primera "solo" morían los perdedores.

Evidentemente, ambas modalidades tenían varios inconvenientes:

a) No eran económicas, pues suponían un gran despilfarro para el editor.

b) Quitaban protagonismo al editor y al público, ya que no se les preguntaba qué hacer con el vencido.

c) Reducían enormemente el número de gladiadores, sin dejar posibilidad de salvar ni siquiera a los buenos, puesto que, si se enfrentaban dos gladiadores excepcionales, necesariamente uno de ellos tenía que morir, lo cual iba en detrimento del espectáculo y del negocio.

Y precisamente Augusto requería del espectáculo gladiatorio para construir y asentar el recién fundado Imperio, de modo que lo que más necesitaba era tener contenta a la gente, exhibirse él mismo en el palco y, por supuesto, muchos gladiadores, cuantos más y más buenos, mejor. Es lógico, por tanto, que prohibiese los sine missione.

En cualquier caso, no parece probable que en los munera sine missione se usasen gladiadores caros, pues no había editor que pudiese financiarlos; tampoco está claro que el espectáculo gladiatorio fuese mejor. Parece, por tanto, que en los sine missione se empleaban únicamente gladiadores novatos (tirones) o de baja categoría y, sobre todo, los damnati ad gladium. De hecho, los condenados a morir con la espada solían ser ejecutados mediante la segunda modalidad de sine missione; en este caso, el damnatus que quedaba vencedor del último combate recibía la muerte de manos de un venator o de un soldado, ya que la sentencia judicial establecía que todos ellos debían morir en la arena a espada. ${ }^{66}$

En su reforma, Augusto también especificó cuántos días de juegos podían darse al año. Además de establecer la medida ya mencionada de que los praetores solo podían ofrecer dos munera legitima mientras estaban en el cargo, con un máximo de 60 gladiadores en cada munus, se estableció también que los sumos sacerdotes del culto imperial de las provincias debían celebrar munera legitima una vez al año, pagados por ellos mismos. Con esta intención, los sacerdotes en las provincias a menudo se encargaban de comprar y entrenar a los gladiadores que iban a emplear en esos juegos. En suma, en las provincias, el sacerdote del culto imperial actuaba como un

65 Suet., Augustus 45.3: gladiatores sine missione edi prohibuit. No obstante, pese a la prohibición, los combates sine missione fueron restablecidos en varias ocasiones.

66 Sen., Epistulae 7.4: victorem in aliam detinent caedem; exitus pugnantium mors est. 
lanista, como constatan hechos como que Galeno trabajó como médico en la familia gladiatoria del sumo sacerdote de Pérgamo.

Otra de sus medidas afectó a la ordenación de los espectadores en la grada y a su vestimenta. Originariamente no había separación de clases en los recintos destinados a juegos y espectáculos públicos. Así, en las carreras en el circo, en los combates de gladiadores en el anfiteatro, o en los espectáculos en el teatro, cada espectador se sentaba en el asiento que quería, o el que primero lo ocupaba. Esta libertad se mantuvo hasta el 194 a.C, en el que, según Livio, hubo por primera vez segregación por clase social, al sentarse el Senado aparte del resto del pueblo, lo que provocó discrepancia de opiniones. ${ }^{67}$ No obstante, nadie tuvo privilegio alguno de asiento, a excepción de los premiados con la corona civica, hasta el año 67 a.C. cuando se aprobó la lex Roscia, por la cual se reservaban a los caballeros las primeras catorce filas de asientos en el teatro y en el anfiteatro. ${ }^{68}$

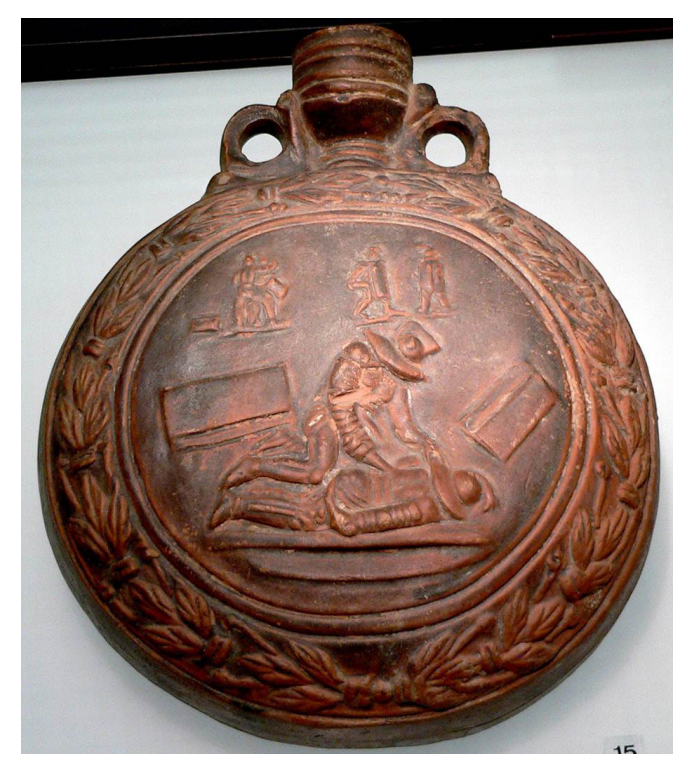

Fig. 8. Cantimplora de cerámica. Museo de Colonia.

Augusto introdujo nuevas medidas. Según cuenta Suetonio, molesto porque durante unos juegos en los que la grada estaba abarrotada, nadie cedió un asiento a un senador, hizo que el Senado decretase que la primera fila quedase reservada para los senadores en cualquier espectáculo público. También se decretaron otras medidas: la separación de los soldados de los civiles; se asignaron asientos especiales a los plebeyos casados y a los jóvenes que aún no habían alcanzado la mayoría de edad se les obligaba a sentarse junto a sus tutores; también se prohibió a la gente vestir capas

67 Liv., 34.54.

68 Liv., Ab Urbe Condita. Periocha 99 (lex Roscia); Desde antiguo, a los condecorados con la corona cívica, se les reservaba asientos especiales en los juegos (Plin., Nat. Hist. 16.5). 
oscuras (excepto a los de las filas traseras) y se confinó a las mujeres a las filas de atrás, a excepción de las Vestales, que debían sentarse frente a la tribuna del praetor ${ }^{69}$ En consecuencia, tras estas medidas, la situación en las gradas era la siguiente: las primeras catorce filas del anfiteatro solo podían ocuparlas los equites, quedando la primera reservada a los senadores. En esencia, cuanto más arriba estuviese uno en la clase social, más cerca de la primera fila se sentaba, y viceversa.

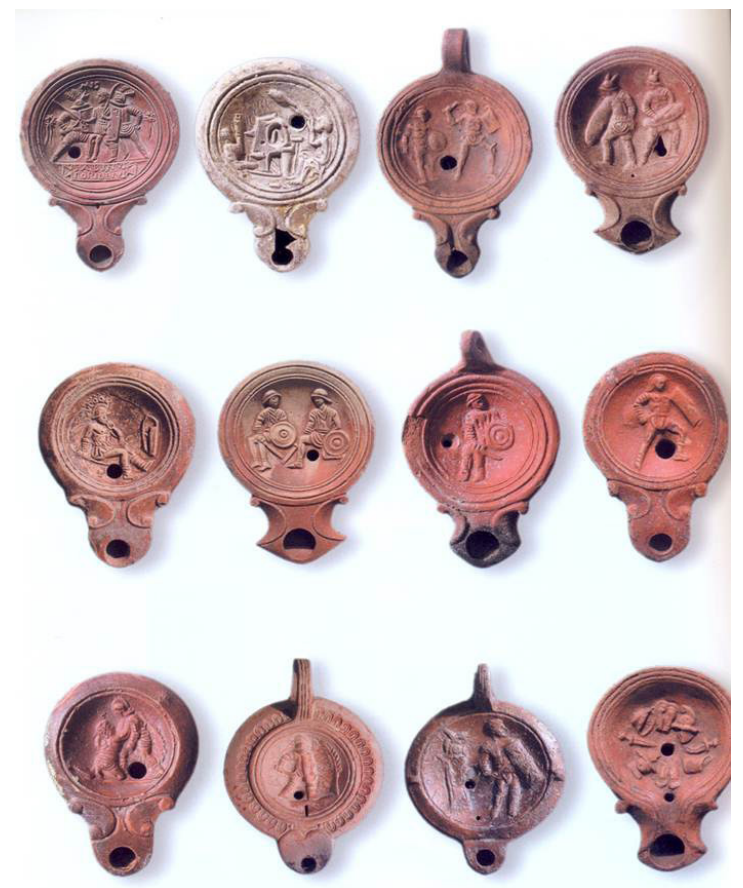

Fig. 9. Lucernas con escenas de luchas de gladiadores.

Sus medidas fueron mantenidas por los emperadores sucesivos. Calpurnio Sículo, de época de Nerón, confirma que las mujeres quedaban en las gradas superiores y junto a ellas, aunque separado, el resto del populacho y los pobres que no tenían toga. Marcial nos informa de que las ropas oscuras estaban prohibidas, y de la asistencia de acomodadores para comprobar los asientos de las primeras catorce filas. Los equites vestían la toga blanca y llevaban el anillo de oro, exclusivo de su clase social. ${ }^{70}$ Los magistrados en oficio vestían la toga praetexta, mientras que los senadores llevaban una ancha raya púrpura sobre su túnica (latus clavus). El emperador a menudo solía asistir con traje triunfal, que consistía en una toga púrpura con motivos en oro o una toga blanca con bordados en oro, muy de moda durante el siglo I. ${ }^{71}$ La mayoría

69 Suet., Augustus 44.

70 Calpur. Sic., Eclogae 7.4-83; Mar., Epigr. 4.2 (togas blancas); 5.14 (acomodador).

71 El traje triunfal no esta referenciado explícitamente durante los munera del Alto Imperio, pero es muy probable que se usase, pues los emperadores solían vestirlo en las grandes ocasiones de estado (Dio. Cas., 
de los ciudadanos también vestía togas blancas, sencillas, y en invierno pequeñas capas blancas (lacernae albae) para protegerse del frío. ${ }^{72}$ Los soldados que habían ganado premios militares (corona civica) estaban autorizados a lucirlos en el teatro ${ }^{73}$ y en el anfiteatro. Las mujeres casadas (matronae) vestían la stola como imponía la lex Iulia theatralis (del 27 al 17 a.C.), mientras que las prostitutas llevaban la toga, la vestimenta masculina, para dejar claro así que habían abandonado toda decencia femenina. ${ }^{74}$

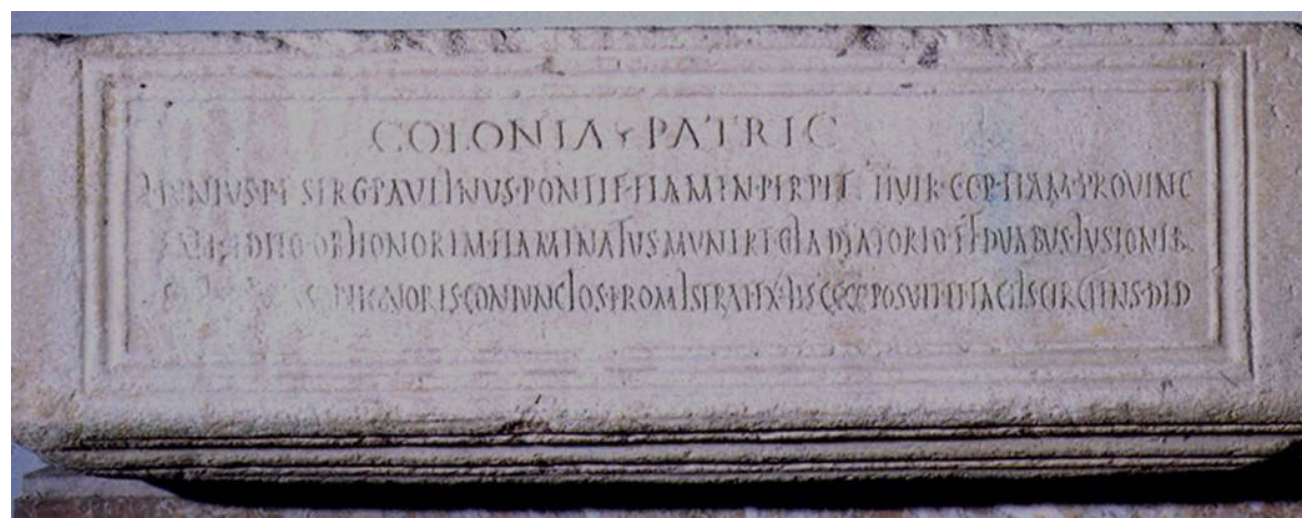

Fig. 10. Magistrado que sufragó en su ciudad natal munera gladiatoria. Museo de Córdoba.

Las Res Gestae, escritas por el propio Augusto, y los datos de Suetonio se centran principalmente en Roma, pero los juegos romanos, especialmente los munera gladiatoria, se extendieron durante el gobierno de Augusto a lo largo de todas las provincias del Imperio, como demuestran la gran cantidad de elementos arqueológicos, escultóricos, epigráficos, musivarios y cerámicos, que han aparecido en todas ellas (Figs. 8-9). Los sumos sacerdotes del culto imperial eran los responsables de que en sus provincias se celebrasen munera legitima una vez al año, sufragados por ellos mismos. A los ciudadanos ambiciosos de las provincias Augusto les ofrecía la posibilidad de ganar algo de notoriedad entre sus conciudadanos y vecinos permitiéndoles sufragar parte de los espectáculos si lo solicitaban voluntariamente (construcción o reparación de anfiteatros), pero sería como una acción evergética (Fig. 10), una aportación de beneficencia a la comunidad, pero en ningún caso algo que pudiera hacer sombra al emperador.

En definitiva, con sus reformas y con la estandarización de reglas, equipo y procedimientos, Augusto institucionalizó los combates gladiatorios como un deporte na-

63.4.3), durante la dedicación de edificios públicos (Dio. Cas., 59.7.1; 60.6.9) u, ocasionalmente, durante las sesiones del Senado (Dio. Cas., 67.54.3). Dio. Cas., 79.9.2 sugiere que era la vestimenta típica del emperador durante los munera a principios del siglo III. Sobre el nuevo traje triunfal blanco, vid. ILS 1763, que da testimonio de un liberto de Nerva praepositus vestis albae triumphalis. Cf. al respecto, VILLE 1981, 440-441.

72 Mar., Epigrammata 14.135.

73 Plin., Nat. Hist. 16.5.13.

74 Sobre prostitutas vistiendo la toga, cf. GARDNER 1986, 251-252. 
cional romano. Tras su largo reinado ya no había vuelta atrás en el modelo de espectáculo gladiatorio que había asentado. A partir de entonces, los espectadores romanos esperaban que, en lo sucesivo, dicho espectáculo mantuviese el mismo esquema; no solo esperaban que los futuros emperadores siguiesen ofreciéndolos, sino también, con la misma frecuencia, características de calidad y formato con el que Augusto se los había ofrecido.

\section{BibLIOGRAFÍA}

AA.VV. (1982): Lo sport nel mondo antico. Ludi, munera, certamina a Roma, Roma.

AA.VV. (2002): Ludi Romani. Espectáculos en Hispania Romana, Mérida.

ÁNGELA, A. (2007): Una giornata nell'antica Roma: vita quotidiana, segreti e curiosità, Milano.

Auguet, R. (1972): Crueldad y civilización. Los juegos romanos, Barcelona.

Augenti, D. (2001): Spettacoli del Colosseo nelle Cronache degli Antichi, Rome.

BEACHAM, R. C. (1991): The Roman Théâtre and Its Audience, London-New York.

BernsteIn, F. (1998): Ludi Publici. Untersuchungen zur Entstehung und Entwicklung der öffentlichen Spiele im republikanischen, Rom-Sttuttgart.

BESTE, H. J. (2001): "I sottorranei del Colosseo: impianto, trasformazioni e funcionamiento", [en] A. La Regina, (ed.), Sangue e Arena, Roma, 277 ss.

Bollinger, T. (1969): Theatralis Licentia. Die Publikurnsdernonstrationern und oxentlichen Spielen in Rom der fruheren Kaiserzeit und ihre, Basilea.

BRICEÑo, S. I. (1896): Los gladiadores de Roma. Estudio histórico, legal y social, Bogotá.

Brown, S. (1992): "Death as Decoration: Scenes of the Arena on Roman Domestic Mosaics", [en] A. Richlin (ed.), Pornography and Representation in Greece and Rome, New YorkOxford, 180-211.

Cagigal, R. (2010): Gladiator. Luchar para vivir en un oficio peligroso, Santander.

CAMEron, A. (1976): Circus Factions. Blues and Greens at Rome and Byzantium, Oxford.

Carcopino, J. (1968): Daily Life in Ancient Rome: The People and the City at the Height of the Empire, Yale.

Ceballos, A. (2003): "Los espectáculos del anfiteatro en Hispania", Iberia 6, 59-69.

CiAnCio, P. - PisAnI, G. (eds.) (1994-1996) : Teatri greci e romani. Alle origini del linguaggio rappresentato, Torino.

Clavel-LÉVÊQue, M.

(1984): L'empire en jeux. Espace symbolique et pratique sociale dans le monde romaine, Paris.

(1986): "L'espace des jeux dans le monde romain: hégémonie, symbolique et pratique sociale", Aufstieg und Niedergang der römischen Welt II.16.3, 2405.

Colini, A. M. - CozzA, L. (1962): Ludus Magnus, Roma.

Corbeill, A. (2002): "Political movement: walking and Ideology in Republican Rome", [en] D. Fredrick (ed.), The Roman gaze: Vision, Power and the body, Baltimore, MD, 183 ss.

Cozzo, G. (1971): Il Colosseo: Anfiteatro romano, Roma. 
Domergue, C. - Landes, C. - Pailler, J. M. (eds.) (1990): Spectacula I: Gladiateurs et amphithéatres. Actes du colloque tenu à Toulouse et á Lattes, 26-29 mai 1987, Lattes.

Dupont, Fl. (1985) : L'acteur roi, ou le théatre dans la Rome antique, Paris.

Evans, J. K. (1980) : "Plebs rústica", AJAH 5, 137 ss.

FINLEY, M. I. (1973): The Ancient Economy, Berkeley.

Flobert, L. (1990): “Quelques suirvivances de la gladiatura”, Voces 1, 71-76.

Franklin, J. (1997): “Cn. Alleius Nigidius Maius and the amphitheatre, munera and a distinguished career at ancient Pompeii”, Historia 46/4, 434-447.

FRIELÄNDER, L.

(1920): Darstellungen aus Sittengeschichte Roms, Leipzig, (3 vols.).

(1965): Roman Life and Manners under the Early Empire, New York.

(1967): “Juegos y espectáculos romanos", Citius Altius Fortius 9, 5-257 (con notas de P. Piernavieja y Dz. Rozitis).

French, D. R. (1985): Christian emperors and pagan spectacles. The secularization of the ludi A.D. 382-525, Berkeley, CA.

Futrell, A.

(1997): Blood in the Arena: The Spectacle of Roman Power, Austin, TX.

(2007): The Roman Games (Historical Sources in Translation), Oxford.

Gabucci, A. (ed.) (1999): Il Colosseo, Milano.

GARDNER, J. F. (1986): Women in Roman Law and Society, London.

Golvin, J. C. (1988): L'amphitéâtre romain: Essai sur le théorisation de sa forme et de ses fonctions, Paris.

Golvin, J. C. - LAndes, C. (1990): Amphitheatres et gladiateurs, Paris.

Grant, M. (1967): Gladiators, London.

Gunderson, E. (1996): “The Ideology of the Arena”, Classical Antiquity 15, 113-151.

Guttmann, A. (1978): From Ritual to Record, New York.

GuILlÉn, J. (1981): Urbs Roma. Vida y costumbres de los romanos, Salamanca.

HopKINS, K.

(1978): Conquerors and slaves, Cambridge.

(1983): Death and Renewal. Sociological Studies in Roman History II, Cambridge.

Hopkins, K. - BeARD, M. (2005): The Colosseum, Cambridge.

Humphrey, J. H. (1986): Roman Circuses: Arenas for Chariot Racing, London.

JACOBElli, L. (2003): Gladiators at Pompeii, Los Ángeles, CA.

JUNKELMANN, M.

(2000): "Familia Gladiatoris: The Heroes of the Amphitheatre", [en] E. Köhne - C. Ewigleben (eds.), Gladiators and Caesars: The Power of Spectacle in Ancient Rome, Berkeley, CA, 35-67.

(2008): Gladiatoren das spiel mit dem tod, Mainz am Rhein.

KYLE, D. G. (2007): Sport and Spectacle in the Ancient World, Oxford.

Koenne, E. - Ewigleben, C. (eds.) (2000): Gladiators and Caesars: The Power of Spectacle in Ancient Rome, Los Ángeles, CA.

KoHn, E. (2000): Gladiators and Caesars: The Power of Spectacle in Ancient Rome, London. 
Kondoleon, C. (1999): “Timing spectacles: Roman domestic art and performance", [en] B. Bergmann - C. Kondoleon (eds.), The Art of Ancient Spectacle, Washington, DC.

LAFAYE, G. (1896): “Gladiator”, [en] Ch. V Daremberg - E. Saglio, Dictionaire des antiquités grecques et romaines, vol. 2, Paris, 1563-1600.

LANDES, C. (1992): Spectacula II. Le theatre antique et ses spectacles. Actes du colloque tenu au Musée Archeologique Henri Prades de Lattes les 27, 28, 29, 30 avril 1989, Lattes.

LANDES, C. (ed.) (1990): Le cirque et les courses de chars à Rome et Byzance, Lattes.

LUCA GREGORI, J. (2011): Ludi e munera, 25 anni di ricerche sugli specttacoli d'etá romana, Milano.

LussanA, A. (1950): “Osservazioni sulle testimonianze di munificenzia privata della Gallia cisalpina nelle iscrizioni latine", Epigraphica 12, 123 ss.

Mancioli, D. (1987): Giochi e Spectacoli. Museo della civilta romana, Roma.

MeIJer, F. (2006): Un giorno al Colosseo. Il mondo dei gladiatori, Roma.

Newbold, R. F. (1975): “Cassius Dio and the Games”, L'Antiquité Classique 44, 604 ss.

Nogales, T. (2000): Espectáculos en Augusta Emerita, Badajoz.

Nogales, T. - SÁnchez Palencia, F. J. (2002) (eds.): El circo en la Hispania romana, Madrid.

PASTOR, M.

(2002): "Munera gladiatorium: aspectos sociales", [en] A. Ortiz - A. Ávila (eds.), Scripta antiqua in honores Ángel Montenegro Duque et José María Blázquez Martínez, Valladolid, 485-499.

(2007): "El uso de la violencia en los munera gladiatoria", [en] G. Bravo - R. González (eds.), Formas y usos de la violencia en el mundo romano, Madrid, 187-202.

(2008): "Los ludi romani como forma de corrupción”, [en] G. Bravo - R. González Salinero (eds.), La corrupción en el mundo romano, Madrid, 395-405.

(2011): "Propaganda electoral y ludi romani", [en] G. Bravo - R. González Salinero (eds.), Propaganda y persuasión en el mundo romano, Madrid, 213-230.

PAStOR, M. - MAÑAS, A.

(2010): “Munus gladiatorum. Origen del deporte espectáculo de masas", Florentia Iliberritana $21,291-321$.

(2012): “Munera gladiatoria. Mujeres gladiadoras”, Florentia Iliberritana 23, 127-151.

PAstor Muñoz, M. - PAstor Andrés, H.

(2008): "Violencia y pasión en los juegos de gladiadores", [en] M. Pastor Muñoz et alii (eds.), Deporte y Olimpismo en el mundo antiguo y moderno, Granada, 163-206.

(2009): "La profesión de gladiador en el norte de África", Florentia Iliberritana 20, 171 199.

(2013a): "Guerra y munus gladiatorium”, [en] A. Pociña - J. M. García González (eds.), La Paz y la Guerra, Granada, 259-276.

(2013b): "Educación y entrenamiento en el ludus", Florentia Iliberritana 24, 127-152.

Piernavieja, P. (1977): Corpus de inscripciones deportivas de la España Romana, Madrid.

Piganiol, A. (1923): Recherches sur le jeux romains, Strasbourg-Paris.

Plass, P. (1995): The Game of Death in Ancient Rome: Arena Sport and Political Suicide, Madison, WI. 
PociñA, A. (1976): "Los espectadores, la lex Roscia theatralis y la organización de la cavea en los teatros romanos", Zephyrus 26-27, 435-442.

Regianni, A. M. (1988): "La venatio: origine e primi rafigurazioni”, [en] M. L. Conforto et alii (eds.), Anfiteatro flavio: immagine, testimonianze, spettacoli, Roma, 148 ss.

RIZAKIS, A.

(1984): “Munera gladiatoria á Patras”, Bulletin de Correspondance Hellénique 108, 533542.

(1990): “Munera gladiatoria à Patras II”, ZPE 82, 201-208.

Robert, L. (1940): Les gladiateurs dans l'Orient grec, Paris.

SchneIDER, K. (1895): “Gladiatoren”, [en] Pauly.Wisowa Real-Encyclopädieder Classischen Altertumswissenschaft, Supl. 3, 760 ss.

ShadraKe, S. (2005): The World of the Gladiador, Stroud Gloucertershire.

TeJa, R. (2002): “Espectáculo y mundo tardío en Hispania”, [en] Ludi Romani. Espectáculos en Hispania Romana, Mérida, 163-170.

Teyssier, E. (2009): La mort en face. Le dossier gladiateurs, Lonrai.

VeYne, P. (1976): Le pain et le cirque. Sociologie historique d'un pluralisme politique, Paris.

VIDAL, C. (2002): "De Ben-Hur a los tres días del gladiador: los ludi en la literatura y el cine" [en] AA.VV., Ludi Romani. Espectáculos en Hispania Romana, Mérida, 159-162.

VisMARA, C.

(1987): "Sangue e arena. Iconografie di supplizi in margine a: Du châtiment dans la cité", Dialoghi di Archeologia 5/2, 130 ss.

(1990): "L'amphithéâtre comme lieu de supplice" [en] C. Domergue et alii (eds.), Spectacula I. Gladiateurs et amphithéâtres, Lattes, 253 ss.

(1999a): "I luoghi dello spettacolo", [en] A. Gabucci (ed.), Il Colosseo, Milano.

(1999b): "I supplizi e i giochi pericolosi”, [en] A. Gabucci (ed.), Il Colosseo, Milano.

Ville, G. (1981): La gladiature en Occident des origines á la mort de Domitien, Paris-Roma.

Weber, C. W. (1986): Panem et circenses, Milano.

Welch, K. (2007): The Roman Amphitheatre from its Origins to the Colosseum, Cambridge.

WiEDEMANN, Th. (1992): Emperors and Gladiators, London-New York.

White, K. D. (1970): Roman farming, London.

ZACCARIA, C. (1994): "Testimonianze epigrafiche di spettacoli teatrali e di attori nella Cisalpina romana", [en] Spettacolo en Aquileia e nella Cisalpina romana, Udine. 